\title{
O cuidado e educação das (os) bebês em contexto coletivo: a construção da experiência da Auxiliar de Apoio à Educação Infantil na interação com Bebês e Professoras
}

\begin{abstract}
Resumo: Este artigo tem por objetivo analisar como a Auxiliar de Apoio à Educação Infantil constrói sua experiência na interação com bebês e professoras, durante as atividades de cuidado e educação em contexto coletivo. Dentre a complexidade de ações que constituem as atividades com bebês no berçário, destacamos as práticas de cuidado. Focalizar tais práticas justifica-se: a) porque o cuidado está no cerne da definição da Educação Infantil; b) na atuação com bebês, as práticas de cuidado têm uma centralidade ainda maior; e c) sendo as ações de apoio às professoras a atribuição das Auxiliares, focalizar tais práticas nos permite compreender os sentidos por elas construídos. O método de construção e instrumento de registro dos dados utilizados foram, respectivamente, a observação participante e o diário de campo. Os resultados permitem identificar elementos da relação entre as Professoras para a Educação Infantil e a Auxiliar de Apoio à Educação Infantil que influenciam a compreensão sobre a indissociabilidade entre as práticas de cuidar e educar bebês em contexto coletivo.
\end{abstract}

Palavras-chave: Docência na Educação Infantil. Professor para a Educação Infantil. Auxiliar de Apoio à Educação Infantil. Cuidado e Educação de Bebês.

\section{Childcare and education of toddlers in a collective context: building the experience of Early Childhood Education Support Assistants through the interaction with toddlers and Lead Teachers}

\begin{abstract}
This paper intends to analyze how Early Childhood Education Support Assistants build experience through the interaction with toddlers and lead teachers, during childcare and education activities, in a collective context. Among the complexity of actions that constitute the activities with toddlers in the nursery, we highlight the childcare practices. Focusing on such practices is justified: a) because childcare is at the heart of the definition of Early Childhood Education; b) when it comes to toddlers, childcare practices have an even greater centrality; and c) since providing support to the teachers constitute the attribution of the Assistants, focusing on these practices allows us to understand the senses they have acquired. The method of research development and the instrument for recording the data used were, respectively, the participant observation and the field diary. The results allow us to identify elements of the relationship between Early Childhood Education Teachers and their Support Assistants, that influence the comprehension about the indissociability between the practices of childcare and education of toddlers in a collective context.
\end{abstract}

Keywords: Teaching in Childhood Education. Early Childhood Education Teacher. Early Childhood Education Support Assistant. ChildCareandEducationofToddlers.

'Doutoranda em Educação pela FaE/UFMG. Mestra em Educação pela FACED/UFBA. Pedagoga e Psicopedagoga. Integrante do Núcleo de Estudos e Pesquisas Sobre Infância e Educação Infantil (NEPEI) da FaE/UFMG. Contato: laiscarolineabit@gmail.com.

${ }^{2}$ Doutora e Mestra em Educação pela FaE/UFMG. Professora do Curso de Pedagogia e do Programa de Pós-graduação em Educação da FaE/UFMG. Pesquisadora do Núcleo de Estudos e Pesquisas Sobre Infância e Educação Infantil (NEPEI) da FaE/UFMG. Contato: isabel.os@vol.com.br. 
docência na Educação Infantil vem merecendo reflexões da área mesmo antes da definição,
pela Lei de Diretrizes e Bases da Educação (LDB), Lei n. 9.394 de 1996 (BRASIL, 1996), de
que o profissional para atuação com crianças na creche e na pré-escola deveria ser o professor.

A mera definição legal, no entanto, não é capaz de dar conteúdo a essa prática, o que supõe considerar as finalidades dessa etapa da educação as quais dependem diretamente das concepções de criança, de infância e de Educação Infantil. Embora possamos hoje considerar que o reconhecimento de que o professor é o profissional adequado para atuar em creches e pré-escolas é um dos consensos que a área construiu, em sua ainda curta história de luta e de presença nos sistemas de ensino, convivemos com indefinições e arranjos nas políticas educacionais municipais que não encontram amparo nem na literatura nem na legislação nacional.

A concepção geral de que cabe ao professor realizar atividades de cuidado e educação tem sido efetivada na prática por meio de inúmeras formas, nem sempre sistematizadas ou mesmo coerentes com o que definem as Diretrizes Curriculares para a Educação Infantil e, até mesmo, com o que consta sobre a docência na Educação Infantil nas propostas pedagógicas (OLIVEIRA-FORMOSINHO, 2002; CERISARA, 1999, 2002; CAMPOS, 1994; OLIVEIRA, 1994; KRAMER, 2002; KISHIMOTO, 1999; PIMENTA, 2006; BARBOSA, 2006, 2010; VIEIRA, 2013; SILVA, 2004, 2007, 2013). Trata-se, portanto, de tema relevante e que demanda investigação e sistematização de modo a favorecer a realização de processos de formação inicial e continuada, bem como um maior conhecimento das práticas em curso. Focalizamos neste artigo a experiência de uma Unidade de Educação Infantil do município de Belo Horizonte.

Em Belo Horizonte, a oferta de Educação Infantil, em rede própria, pelo município, teve o início de seu processo de expansão em 2003, com a criação das Unidades Municipais de Educação Infantil - UMEIs e do cargo de "Educador Infantil". Em 2012, esse cargo foi transformado em "Professor para a Educação Infantil". Até 2015, somente professoras e professores (com formação mínima em Nível Médio na Modalidade Normal) podiam assumir, mediante aprovação em concurso público, o trabalho direto com as crianças, em jornada diária de 4 horas e meia. A partir desse ano, a Secretaria Municipal de Educação de Belo Horizonte institui o cargo de "Auxiliar de Apoio à Educação Infantil”, com exigência de formação em Nível Médio completo sem habilitação em magistério, idade mínima de 21 anos para os candidatos e estabelecimento de regime de trabalho de acordo com as normas da CLT, com 44 horas de jornada semanal (8 horas diárias) e contratação por meio das Caixas Escolares (GERÊNCIA..., 2015). O Ofício 277/2015, da Gerência Central de Educação Infantil - GECEDI orienta: "em hipótese alguma, este profissional terá autonomia para responder pela turma ou assumir sua responsabilidade" (GERÊECIA..., 2015, negrito do documento). As atribuições do Auxiliar são: 
- Auxiliar o professor, a partir de sua orientação, em atividades educativas, nas turmas de 0 a 2 anos, de jornada integral: rodinha, parquinho, saída da instituição, distribuição de materiais, organização dos pertences das crianças, organização dos espaços para serem utilizados e outras atividades corriqueiras sob a coordenação do professor.

- Auxiliar e/ou realizar atividades de vida diária, a partir da orientação do professor, nas turmas de jornada integral, de 0 a 2 anos de idade - alimentação, banho, repouso, acompanhar crianças ao banheiro, trocas. (GERÊNCIA..., 2015, negrito do documento).

Embora seja uma situação nova na rede municipal de Belo Horizonte, a presença de um Auxiliar em turmas de Educação Infantil já era uma realidade em diferentes redes de ensino públicas e particulares. Em nossa revisão de literatura, encontramos poucos trabalhos que analisam as condições de exercício dessa função, bem como suas repercussões sobre a experiência dos bebês e crianças de até 2 anos. Assim, consideramos importante refletir sobre essa opção, levando-se em conta também que ela não está prevista na legislação que, como mencionamos acima, prevê apenas o professor como o profissional que se responsabiliza pelos processos de cuidado e educação das crianças na Educação Infantil. A pesquisa procurou então compreender as repercussões sobre as práticas com as crianças e, também, como as professoras e Auxiliares compreendem o fazer docente e demais práticas com os bebês no contexto educativo. Focalizamos a experiência das Auxiliares por meio da discussão da seguinte questão: Como a Auxiliar de Apoio à Educação Infantil constrói sua experiência na interação com as(os) bebês e suas professoras, durante as atividades cotidianas de cuidado e educação ? Dessa forma, abordamos a constituição dos sentidos sobre a docência e o trabalho de cuidado e educação de bebês e crianças de até 2 anos.

\section{O cuidado como categoria analítica}

Dentre a complexidade de ações que constituem as práticas cotidianas de professoras e auxiliar com as(os) bebês na instituição pesquisada, destacamos as práticas de cuidado. Conscientes de que qualquer recorte analítico implica em deixar de fora elementos tão importantes quanto a escolha feita, focalizar tais práticas justifica-se, por um lado, porque o cuidado está no cerne da definição da Educação Infantil. Por outro lado, na atuação com as(os) bebês, as práticas de cuidado têm uma centralidade ainda maior. E, sendo as ações de apoio às professoras a atribuição das Auxiliares de Apoio à Educação Infantil, especialmente as ações de cuidados com os bebês e crianças de até 2 anos, focalizar tais práticas nos permitirá compreender os sentidos por elas construídos.

O cuidado se tornou objeto de análise no campo acadêmico, principalmente nas áreas da Enfermagem, Filosofia, Ciências Sociais, Psicologia e Educação, campos que se interessam por conhecimentos relacionados à própria condição humana. Maranhão (2011) destaca a condição híbrida natureza-cultura dos humanos, o que significa que "as dimensões psicológica, social e biológica estão intrincadas, como fios que compõem um tecido e que não podem ser separados sem desmanchá-los" (MARANHÃO, 2011, p. 16). Assim, a abordagem desse objeto complexo exige a mobilização de 
conhecimentos de áreas distintas de modo a favorecer tanto sua compreensão quanto práticas adequadas aos objetivos de promover o desenvolvimento e o bem-estar das crianças nas Instituições de Educação Infantil.

Enquanto categoria no campo da sociologia do trabalho, o "Carework" ou o trabalho do Care logra "expansão na economia de serviços em escala internacional", por múltiplas causas (HIRATA, GUIMARÃES, 2012, p. 1). Entre as principais causas, Hirata e Guimarães (2012) citam a junção de dois fatores: Os cuidados com os idosos dependentes, ocasionados pelo envelhecimento rápido da população nos países industrializados. E, acrescido ao envelhecimento da população, a entrada maciça da mulher no mercado de trabalho, que enfrenta dificuldades para administrar os cuidados domiciliares com os membros dependentes da família (HIRATA, GUIMARÃES, 2012, p.1). Dessa forma, as atividades que consistem em cuidar dos outros, vão sendo terceirizadas em razão da complexidade existente nas organizações familiares (HIRATA, GUIMARÃES, 2012, p. 1) e a creche, nesse contexto, se constitui em uma das instituições que se ocupam do trabalho do cuidado (carework) em contexto coletivo.

Para Hirata, Guimarães e Sugita (2012) o cuidado (care) significa, de forma geral, “o conjunto de medidas públicas necessárias para o bem-estar (welfare) da população num Estado-providência" (HIRATA, GUIMARÃES e SUGITA, 2012, p. 82). As autoras nos lembram da diversidade de significações que o verbo cuidar tem na língua portuguesa que designa, no Brasil, "um espectro de ações plenas de significado nativo, longa e amplamente difundidas, muito embora difusas no seu significado prático" (HIRATA, GUIMARÃES e SUGITA, 2012, p. 82). Para as autoras as noções de "cuidar" e "tomar conta" são expressões de uso cotidiano que possuem vários significados, são atividades associadas a agentes femininos e subalternos, bem como compartilham uma natureza multidimensional e transversal com outros conceitos como "trabalho" e "gênero". Nas palavras das autoras,

o "cuidar da casa" (ou "tomar conta da casa"), assim como o "cuidar das crianças" (ou "tomar conta das crianças") ou até mesmo o "cuidar do marido", ou "dos pais", tem sido tarefas exercidas por agentes subalternos e femininos, os quais (talvez por isso mesmo) no léxico brasileiro têm estado associados com a submissão, seja dos escravos (inicialmente), seja das mulheres, brancas ou negras (posteriormente) (HIRATA, GUIMARÃES e SUGITA, 2012, p. 82).

Molinier (2012) afirma que a origem das teorias do care ocorreu por volta dos anos 1970 e está vinculada ao campo da psicologia do desenvolvimento moral a partir de estudos realizados por Carol Gilligan. Segundo Molinier (2012), "Gilligan evidenciou a existência de uma voz, moral diferente, ou seja, uma forma diferente de resolver dilemas morais, baseada não nos critérios da lei e da imparcialidade como acontece na ética da justiça, mas em critérios relacionais e contextuais" (MOLINIER, 2012, p. 29, itálico da autora). O que Gilligan chamou de "vOz moral diferente", ainda segundo Molinier, foi confirmado posteriormente pela filósofa política Joan Tronto, ou seja, que era uma "voz", de maioria feminina, "cuja experiência moral baseavase em atividades que consistiam em cuidar dos outros" (MOLINIER, 2012, p. 29).

Para compreender melhor o care em termos de experiência vivida, Molinier (2012) apresenta reflexões a partir de cinco descrições: a) o care como gentleness; b) o care como savoir-faire discreto; c) o care como trabalho sujo; d) o care como trabalho inestimável e e) o care como narrativa política. Afirmando que somos todos "provedores e beneficiários de care e, todos dependentes" Molinier (2012, p. 41) traz 
reflexões sobre o cuidado baseado na atividade, na vida, na saúde e nas interdependências. Das características mais visíveis apresentadas pela autora na argumentação sobre as atividades do cuidado, a partir das descrições acima, elaboramos a Tabela 01, na sequência.

TABELA 01: características apresentadas por Molinier na argumentação sobre as atividades do cuidado como carework

\begin{tabular}{ll}
\hline & Forma de agir, gestos, atenção particular e respostas ajustadas ou afinadas às \\
Competências & necessidades do destinatário \\
\cline { 2 - 2 } naturalizadas & Discrição, simpatia, tato \\
\cline { 2 - 2 } historicamente & Capacidade de antecipação, atitude atenciosa e desapegada \\
\cline { 2 - 2 } como femininas & Amor, doçura, feminilidade, paciência, generosidade e sutileza \\
\cline { 2 - 2 } & Vida, saúde e interdependência \\
\hline
\end{tabular}

Como podemos verificar na Tabela 01, o trabalho do cuidado, como dito, exige competências que foram naturalizadas historicamente como femininas, como afirma a autora, "naquilo que é esperado das mulheres" na configuração da sociedade (MOLINIER, 2012, p. 33). Outro elemento importante para análise é o fato dessas atividades não proporcionarem um resultado material concreto visível, ou seja, são atividades que, segundo Molinier (2012), estão postas a partir das interações e, quando bem feitas, não são vistas, além de serem atividades que não se resumem a habilidades técnicas e que são necessárias em qualquer setor da sociedade.

Dessa reflexão, gostaríamos de chamar atenção a três aspectos que consideramos importantes. O primeiro é o que Molinier (2012) chama de “o carecomo trabalho sujo" que está, "conceitualmente sob o aspecto da relação com o corpo e com a morte" (MOLINIER, 2012, p. 35). A autora traz o exemplo das auxiliares de enfermagem que cuidam dos trabalhos relacionados aos excrementos do corpo humano e às necessidades vitais, sejam elas de alimento, de vestimenta ou de higiene pessoal. Para Molinier (2012), no sentido atribuído ao care como trabalho sujo, "os atores e atrizes do care não são heróis, são ambivalentes, defensivos, eivados de contradições, de conflitos entre seu próprio interesse e os interesses dos outros" (MOLINIER, 2012, p. 35). As características da atenção às crianças de 0 a 3 anos na Educação Infantil envolvem, igualmente, as relações com o corpo e seus excrementos, com a proteção à vida e a promoção da saúde, nesse caso, com sujeitos sadios. Também nas instituições de Educação Infantil e mais fortemente na etapa creche, o trabalho é desenvolvido, com raras exceções, por mulheres. Quando existe a figura da auxiliar reproduz-se, na instituição de Educação Infantil, a posição hierarquicamente inferior em relação às professoras.

O segundo é o que ela chama de "carecomo narrativa ética" que está, segundo a autora, vinculado a concepções estereotipadas das representações dos diferentes papeis assumidos na sociedade pelo feminino. Para a autora

a atenção dada ao que conta, transforma a visão estereotipada do carecomo expressão do amor (das mães, das famílias, até mesmo das cuidadoras) ou sua derrapagem estigmatizante rumo a má reputação (mães isoladas, cuidadoras que maltratam...) para 
interessar-se por visões morais particulares onde a preocupação com os outros expressa-se através de atividades concretas, mais ou menos agradáveis, que solicitam sentimentos ou afetos por vezes penosos, contraditórios, ambivalentes e marcados por defesas (MOLINIER, 2012, p. 41).

O terceiro aspecto se refere ao que Hirata e Guimarães chamam de "care remunerado", o trabalho de cuidado realizado em contexto institucional, de forma coletiva que, segundo elas, ainda desafia as análises, por ser bastante tênue a fronteira entre o trabalho de cuidado remunerado e o trabalho de cuidado não remunerado. As autoras afirmam que o trabalho do care "é ao mesmo tempo trabalho emocional e trabalho material, técnico", que por consequência, envolve conceitos que de um lado, "parecem ser do domínio exclusivo das famílias", como o amor, o afeto e as emoções e de outro lado, não antagônico, parecem ser "de domínio exclusivo das 'cuidadoras', das 'acompanhantes', das 'auxiliares' remuneradas", sendo nele, também indissociáveis "postura ética, ação e interação" (HIRATA, GUIMARÃES, 2012, p. 3).

Para Soares (2012) o trabalho de cuidar do outro envolve diferentes dimensões e atividades que dependem tanto da pessoa que se ocupa das atividades de cuidado, quanto da pessoa que será o objeto do cuidado, sendo essa interação mediada pela família de quem recebe o cuidado. Nas palavras do autor,

os atores que compõem essa relação são, dessa maneira, determinantes do tipo de interação que será estabelecida no trabalho de cuidar. Trata-se de relações desiguais perpassadas por assimetrias socialmente estabelecidas de gênero, idade, classe social, raça e etnia, que se recobrem parcialmente, que implicam um exercício de poder e exigem qualificações específicas (SOARES, 2012, p. 45).

As dimensões que são necessárias para compreender a complexidade das atividades de trabalho do cuidado, de acordo com Soares (2012) são: a) a dimensão física, que trata do esforço corporal mobilizado nos atos de segurar, deslocar, sustentar os atores que recebem os cuidados; b) a dimensão cognitiva, que trata dos conhecimentos técnicos sobre as atividades de cuidado; c) a dimensão sexual, que trata das atividades que envolvem o contato com o corpo do outro, por exemplo, as trocas de fralda e o banho; d) a dimensão relacional, que trata das qualificações sociais. Soares (2012) busca em Goffman (1967) a definição deste conceito, definindo esta dimensão como "a capacidade de evitar o embaraço para si e para o outro"; e e) a dimensão emocional, que trata dos laços interpessoais e dos vínculos com diferentes estruturas sociais e culturais, sustentando que o trabalho do cuidado exige uma coordenação do eu e das próprias emoções, necessitando, também, de gerir as emoções da pessoa que recebe o cuidado. Soares (2012) reconhece como importante, ainda, a consideração da intercessão entre as dimensões do trabalho de cuidar.

\section{Cuidar e educar: como se realizam nas interações entre professoras e a auxiliar de educação infantil}

A literatura dedicada à Educação Infantil revela um processo de construção da concepção, hoje largamente aceita pelos estudiosos da área, de indissociabilidade entre cuidado e educação (SILVA, 2016). No artigo Educação Infantil no Brasil, Silva (2016) discute esse processo por meio da análise da produção acadêmica da área a partir dos anos 1970. Nesse trabalho, observa-se que, de uma visão inicial 
compensatória da expansão da educação da criança de 0 a 6 anos Brasil, caminha-se, juntamente com os movimentos de luta por creches e pré-escolas, para o reconhecimento das crianças como sujeitos de direitos. Nessa direção, as orientações iniciais do atendimento a essas crianças, especialmente nos primeiros anos de vida e em período integral, são problematizadas por meio da crítica às visões que tratavam as populações pobres como incapazes de cuidar e educar seus filhos e filhas. Ao contrário, em diálogo com estudos sobre as crianças e as infâncias, constroem-se referências que reconhecem as potencialidades das crianças desde os primeiros meses de vida e suas possibilidades de se beneficiarem de experiências em contexto coletivo (SILVA e VIEIRA, 2008; FARIA, 2005). E, um dos aspectos fundamentais dessas concepções que hoje orientam os documentos e a produção acadêmica da área, é justamente a ideia de que cuidar e educar são ações indissociáveis e que se interpenetram, na medida em que em cada uma delas as duas dimensões estão presentes.

A revisão da literatura indica que tanto o reconhecimento pleno das crianças como sujeitos de direitos quanto o princípio da indissociabilidade entre cuidado e educação constituem-se em desafios. Pesquisas realizadas em creches brasileiras, nas quais foram realizadas observações e entrevistas com professoras e outros profissionais, concluíram que tais elementos são ainda fragilmente incorporados nas referências que os orientam. Ainda assim, a reflexão por esses atores nos processos de pesquisa permitiu compreender que tais práticas movimentam valores, sentimentos e lógicas que englobam ações que mobilizam tanto dimensões intelectuais, quanto dimensões afetivas da experiência humana. (MONTENEGRO, 2005; DUMONT-PENA, 2015; MARANHÃO, 1998, 2000, 2007; BECKER e MARTINS, 2013; AMORIM, 2011; CORDEIRO, 2005). Importante salientar que bem poucos trabalhos analisaram as especificidades do cuidar e educar com crianças menores de 2 anos.

Um dos primeiros trabalhos que tematizaram especificamente o cuidado como conceito e como prática foi o de Montenegro (2005). A autora propõe uma educação para o cuidado que considere como valores o direcionamento da afetividade e da emotividade. Discute a importância do desenvolvimento do cuidado de si como parte integrante da educação moral das educadoras infantis, propondo a junção dos campos afetivo e cognitivo das ações de cuidar e educar de forma indissociada. Para a autora,

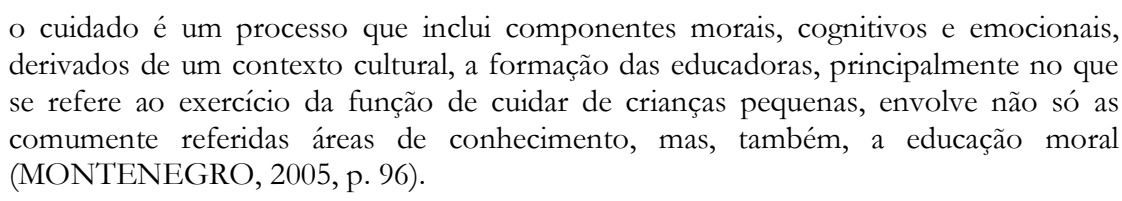

Segundo a autora, a educação moral deve ser pautada na contribuição de um processo de desenvolvimento pessoal, sensível às necessidades do outro e com uma visão crítica dos modelos comumente utilizados numa educação moral. A concepção de moralidade, para Montenegro (2005) não deve se limitar "à noção de justiça como direito universal, portanto impessoal - não deixando de reconhecer sua importância -, mas reconheça o caráter pessoal na resolução de conflitos morais" (MONTENEGRO, 2005, p. 97). 
Outro aspecto que destacamos são as reflexões realizadas sobre a definição da formação dos professores para atuar nessa área. Campos (1999), três anos após a LDB definir a Educação Infantil como primeira etapa da Educação Básica, defende que para atuar com bebês e crianças de 0 a 5 anos os profissionais precisam conhecer as especificidades de cada criança, bem como sua realidade cultural e social. A autora, dentre outras questões, sugere uma formação dos professores que priorize "as especializações pelas subfaixas etárias entre 0 e 10 anos" (CAMPOS, 1999, p.138). Para ela, enquanto no Brasil, os professores que atuam na Educação Infantil são historicamente professores com menores formações, muitos "leigos" e de maioria feminina,

na maioria dos países há uma diversificação do tipo de formação prévia exigida dos professores e educadores que atendem bebês e crianças muito pequenas (até 2 ou 3 anos), crianças na faixa pré-escolar (dos $2 / 3$ anos até 5 ou 6 anos) e crianças de escola primária (dos 6/7 anos até os 10, 11 ou 12 anos, conforme o país) (CAMPOS, 1999, p. 138).

O cuidado e educação das crianças "consiste numa atividade marcada pela origem social das crianças e das educadoras" (SILVA, 2004, p. 284), em um processo de enfrentamento de desafios e de construção de identidades que incorpora e reelabora diversos elementos relacionados às práticas docentes na Educação Infantil. As práticas de cuidado e educação são intrínsecas às atividades diárias de professoras e de auxiliares que atuam com as(os) bebês. Assim, o atendimento na creche com vistas ao desenvolvimento integral das(os) bebês, observando os aspectos físico, psicológico, emocional, afetivo, cultural e social, como orientam a literatura e os documentos normativos da área, supõe que as professoras e as auxiliares atentem para todas as especificidades do trabalho de cuidar e educar de forma indissociada. E, no exercício de suas funções, professora e auxiliar realizam uma infinidade de ações que envolvem o próprio corpo e os das crianças, a mobilização de valores, conhecimentos e afetos e um sem número de decisões ao longo da jornada. Sendo assim, a compreensão dos sentidos de suas ações contribui para a compreensão das práticas educativas na Educação Infantil e, consequentemente, das experiências de adultos e crianças nesse contexto.

Com o objetivo de apreendermos os sentidos desse trabalho para professoras e para a Auxiliar de Apoio à Educação Infantil, realizamos a pesquisa em uma Unidade Municipal de Educação Infantil, em Belo Horizonte, contando com 10 sujeitos de pesquisa: 09 Professoras para a Educação Infantil e 01 Auxiliar de Apoio à Educação Infantil, assim distribuídos: a) 3 professoras no turno da manhã; b) 3 no turno da tarde; c) 3 no turno intermediário; e d) 1 auxiliar que trabalha nos dois turnos.

As observações realizadas voltaram-se para as interações entre as adultas e entre elas e os 12 bebês, cujas idades, em julho de 2017, variavam entre 08 e 13 meses de vida. Os dados aqui discutidos foram construídos por meio da observação participante. Este instrumento da abordagem qualitativa de pesquisa (MINAYO, 2012), tem nos auxiliado na descrição das práticas das professoras e da Auxiliar de Apoio à Educação Infantil, com relação aos cuidados e educação das(os) bebês. Foram realizadas 233 horas de observação no período de março a julho de 2017, utilizando como instrumento de registro, o diário de campo.

Durante as duas primeiras semanas do mês de março os registros das observações foram realizados após o tempo de permanência da pesquisadora no berçário, visto que os vínculos entre os 
sujeitos da pesquisa e a pesquisadora precisariam ser construídos. Após este período de inserção, pudemos introduzir o computador e anotar, tanto quanto possível, os diálogos, gestos, compartilhamentos de ações, impressões e ações realizadas por professoras e pela auxiliar durante a experiência de cuidar e educar bebês. Durante o período de observação, acompanhamos o turno matutino, o turno intermediário, o turno vespertino ${ }^{3}$ e, por vezes, permanecemos todo o dia. Organizamos os dados construídos seguindo as orientações da Análise de Conteúdo (BARDIN, 2011), classificamos e categorizamos os registros, apresentando-os de forma sintética em tabelas que permitem melhor visualização.

Professoras e Auxiliar da Educação Infantil: interações durante as atividades diárias de cuidar e educar bebês

Durante os meses de março, abril e maio ${ }^{4}$, permanecemos 36 dias em campo, computando $61 \%$ dos dias letivos desse período, com um total de 233 horas de observação. Dos apontamentos realizados durante esse período, registramos 540 diálogos e compartilhamento de ações entre as adultas, o que estamos chamando neste artigo de interações. Durante a rotina diária, as professoras dos turnos matutino e vespertino interagem entre si e com os bebês por $3 \mathrm{~h}$. As interações entre as professoras do turno intermediário e os bebês ocorrem em 1:30h e a auxiliar interage com professoras e bebês durante 8 horas. Apresentamos, a seguir, a análise de observações e registros das interações durante a rotina diária de atividades no berçário que ocorrem nas práticas de cuidar e educar bebês, bem como fazem parte da constituição da experiência de trabalho da auxiliar na interação com as professoras e com as(os) bebês.

Das 540 interações registradas, 232, ou seja, 43\% delas foram entre as Professoras e a Auxiliar. Classificamos as interações de acordo com seu conteúdo, tanto inferido, quanto expresso por meio de uma categorização não apriorística. Dentre as situações descritas encontram-se atividades que foram realizadas somente por professora, somente pela auxiliar e aquelas realizadas conjuntamente entre professoras e auxiliar. Essas atividades estão distribuídas de acordo com o seu conteúdo, nas cinco categorias apresentadas na Tabela 02.

INTERAÇÕES ENTRE AS PROFESSORAS E A AUXILIAR

Interações que culminam em informações fornecidas pela auxiliar às professoras sobre as(os) bebês e sobre as atividades diárias.

Interações que culminam em influência da auxiliar em atividades planejadas e/ou realizadas pelas professoras.

Interações que expressam expectativas das professoras e da auxiliar com relação às atividades diárias com as(os) bebês e com relação ao desenvolvimento das(os) bebês.

Interações que culminam em solicitação por parte das professoras para
NÚMERO DE OCORRÊNCIAS

54

54

27

\footnotetext{
3 O turno matutino corresponde ao horário das 7:00h às 11:30h. O turno intermediário das 11:30h às 13:00h, período em que se encerra o turno da manhã e inicia o turno da tarde, respectivamente. O turno vespertino acontece das 13:00h às 17:30h.

4 Apresentamos análises de dados construídos nos primeiros meses do ano letivo, nos quais as(os) bebês estão em processo de inserção na UMEI. Nos meses que seguem para o final do ano, esta mesma análise poderá apresentar resultados diferentes, visto que as professoras e a auxiliar teriam construído vínculo com as crianças, bem como teriam maior conhecimento sobre as características, necessidades e preferências das(os) bebês.
} 


\begin{tabular}{lc}
\hline que a auxiliar realize atividades de cuidado e educação. & 26 \\
Interações que expressam cuidado entre as adultas, bem como & \\
informações diversas: contexto político do país; vida pessoal; & 10 \\
adoecimentos; uniformes; educação dos filhos; outros trabalhos; etc. & TOTAL \\
\hline
\end{tabular}

Fonte: dados da pesquisa, 2017

As atividades diárias realizadas pela Auxiliar identificadas são: troca de fralda; alimentação; banho; contato com bebês, famílias, professoras, coordenação, vice direção e outras profissionais da instituição; acalento; apoio ao sono; organização de ambiente; auxílio nas atividades propostas; e registro das atividades nas agendas individuais das(os) bebês. As professoras realizam, além das atividades acima listadas, preenchimento de planilhas, relatórios, planejamentos, organização de projetos, anamneses, reunião com os responsáveis pelas crianças, portfólios e registros no caderno de comunicação entre os turnos. Observa-se que entre professoras e auxiliares, embora haja, na turma observada, coincidência de algumas ações com a professora também realizando atividades caracterizadas como de cuidado com o corpo das crianças e com o ambiente, há uma clara divisão de tarefas em que a professora ocupa o lugar de maior controle do processo de trabalho. Embora a literatura da área tenha mostrado que também a professora de educação infantil acaba sendo, no sistema educacional, a que ocupa a posição de menor reconhecimento social, com piores carreira e salários, verifica-se aqui mais uma clivagem, com a criação de uma função subordinada à da professora. É o que prevê o documento que o cargo de auxiliar na rede pesquisada (GERÊNCIA..., 2015), confirmando o que os estudos sobre o care identificaram para as pessoas que se dedicam aos cuidados com o corpo e com o ambiente (HIRATA, GUIMARÃES E SUGITA, 2012; MOLINIER, 2012).

No que se refere às interações entre as adultas no ambiente do berçário, a Tabela 02 mostra que a maior incidência caracteriza-se por informações sobre as(os) bebês e/ou sobre a rotina, fornecidas pela Auxiliar que auxilia as Professoras na realização das atividades de cuidar e educar, como se pode ver nos trechos do diário de campo reproduzido a seguir:

Numa atividade de alimentação a Professora, colocando a comida no prato para oferecer ao bebê, pergunta para a Auxiliar: “a clara você faz o que?", a Auxiliar responde que os bebês não têm gostado muito do ovo e que ela deixa separado e vai oferecendo aos pouquinhos(notas de campo, 2017).

Em uma situação de apoio para o sono, a Professora, embalando a bebê nos braços, pergunta à Auxiliar: “o que você acha de colocar ela no berço?”. A Auxiliar responde: "tenta. Toda vez ela acorda". A professora continuou embalando a bebê nos braços, pois tentou coloca-la no berço e, como previsto pela auxiliar, ela acordou. Em seguida a professora tentou colocar a bebê no carrinho por duas vezes, ela chorou e a professora a pegou novamente no colo, mas logo colocou a bebê no carrinho sob protesto, conversando com ela. 8 minutos depois da primeira tentativa da professora de colocá-la no berço, a auxiliar se aproximou do carrinho e falou para a bebê: "pode parar de chorar. Não senhora", saindo com ela da sala. 7 minutos depois a auxiliar voltou para a sala com a bebê adormecida no carrinho e a colocou no cantinho do sono (notas de campo, 2017).

Outro exemplo acontece em um momento de intervenção da professora com um bebê: 
O bebê ainda não senta sozinho. A professora o colocou de bruço e incentivava o bebê a se movimentar, oferecendo a ele um objeto: "toma, vem pegar aqui". Ela colocou um brinquedo um pouco afastado do bebê e tentava fazê-lo sair do lugar sozinho. Ele tentou uma vez e não conseguiu. Chorou. A professora falou com ele: “a gente não desiste fácil das coisas assim não. Vem pegar”. O bebê chorava. A professora o pegou no colo e comentou em voz alta que tenta colocar ele de bruço, mas ela acha que essa posição o incomoda e que o bebê não se sente seguro para ficar de bruço. A auxiliar verbaliza: “no outro turno a gente coloca”(notas de campo, 2017).

Nos exemplos acima observam-se dúvidas por parte da professora, as quais são sanadas pela Auxiliar. Não aparece, no entanto, qualquer referência a conhecimentos que embasem a decisão de ofertar ou não a clara de ovo ou mesmo sobre a adequação de se colocar bebês de bruços, conhecimentos que deveriam estar presentes na formação dessas profissionais, os quais são objeto de estudo do campo da saúde. MARANHÃO et. al. (2015) destacam que o cuidado é um objeto de estudo complexo que exige perspectivas de diferentes campos do conhecimento. Do ponto de vista da educação, a dimensão cultural e, especialmente, as possibilidades de desenvolvimento dos bebês constituem-se na orientação das ações. Do ponto de vista da saúde, a dimensão nutricional e de segurança de oferta de determinados alimentos nessa faixa etária e de posição para dormir são conhecimentos a serem mobilizados. O que se observa na cena acima descrita são decisões tomadas com base no senso comum e, especialmente, em práticas correntes no berçário e na observação da Auxiliar que é quem passa o dia todo com as crianças. Dessa forma, a auxiliar transmite informações sobre os cuidados com os bebês realizados nos turnos em que as professoras não estavam presentes, como no relato acima e no exemplo a seguir:

A Professora verificou nas agendas quem precisava de troca de fralda e verbalizou em voz alta: "todo mundo tem que trocar fralda. Todo mundo viu". A Auxiliar fala para ela que a troca de um determinado bebê já tinha sido realizada por outra professora e que o procedimento pode não ter sido anotado por esquecimento da Professora (notas de campo, 2017).

Observamos também que a Auxiliar influencia nas atividades planejadas e/ou realizadas pelas professoras. As professoras tanto demandam ajuda no cumprimento da rotina, quanto permitem que a Auxiliar influencie nas decisões que são tomadas por elas. Uma intenção de intervenção da Professora com um bebê, por exemplo, pode não se concretizar por sugestão da Auxiliar, como podemos verificar no trecho extraído do diário de campo:

A Professora comentou em voz alta: “a mãe dele pediu para colocarmos ele de bruço". A Auxiliar interferiu: "ele comeu agora. Deixa dar um tempo". A professora aceitou a sugestão da auxiliar e não colocou o bebê de bruço (notas de campo, 2017).

A Auxiliar pode interferir em algumas atividades planejadas e/ou realizadas pelas professoras, auxiliando-as no cumprimento da rotina o que, às vezes, prescinde da comunicação verbal direta:

A Professora oferecendo água a um bebê, perguntou a outro bebê, que estava mais distante dela: “quer água também?”. A Auxiliar, que estava sentada no tapete, levanta em silêncio e entrega a mamadeira com água ao bebê (notas de campo, 2017).

As professoras fazem uma lista de prioridade para a realização das trocas das fraldas. Segundo elas, a prioridade é do bebê que está com a fralda de cocô, em segundo lugar o bebê que está há mais tempo sem troca. Elas decidem de acordo com o seu julgamento as necessidades de cada um. Observamos que elas 
procuram realizar as trocas de fralda de cada bebê em intervalos de, no máximo, 2 horas. No exemplo a seguir, a Auxiliar modificou a rotina, tomando a liberdade de alterar a prioridade das trocas:

Um bebê acordou. Estava há muito tempo sem realizar a troca da fralda porque dormia. A auxiliar ofereceu suco para ele e falou com a professora: “deixa a professora voltar do fraldário com o outro bebê que eu vou levar este. Ele tem mais urgência não é?" A professora confirmou (notas de campo, 2017).

Podemos perceber, ainda, que a Auxiliar possui informações que as professoras demoram um pouco mais para adquirir pela limitação temporal de convivência com as crianças e construção de vínculos afetivos.

Durante o processo de inserção de uma bebê, as professoras comentavam sobre o seu comportamento. Uma Professora falou com a Auxiliar: "ela fica com você, mas é bom. Agora ela tem alguma referência. Daqui a pouco ela vai gostar de outras pessoas. Isso é bom. É porque você fica o dia todo".

Em outro momento, num horário destinado ao sono, a Professora olha o horário que a bebê dormiu na agenda e comenta: "não sei se ela vai dormir". A Auxiliar responde: “essa daqui? Só basta colocar ela no carrinho que ela já está dormindo. Dorme por nada" (notas de campo, 2017).

No levantamento bibliográfico realizado para a construção desta pesquisa, identificamos que a maior parte das teses e dissertações sobre o cuidado e educação de bebês está relacionada a concepções e implicações pertinentes às práticas das adultas com as crianças (HADDAD, 1997; COUTINHO, 2002; NAZARIO, 2002; VITTTA, 2004; GUIMARÃES, 2008; NASCIMENTO, 2009).

A observação do cotidiano do trabalho dessas Professoras e da Auxiliar de Apoio à Educação Infantil permitiu identificar que esta última exerce um papel fundamental na integração das ações entre os turnos. O fato de a Auxiliar permanecer com o mesmo grupo de crianças durante toda a jornada permitelhe maior conhecimento de suas características, necessidades e preferências, o que é comunicado às Professoras. Embora essa ação não esteja prevista entre as atribuições de seu cargo, observa-se que essa prática parece ter se tornado possível diante da abertura das professoras em ouvir e, até mesmo, demandar informações e opiniões da Auxiliar. Da mesma forma, os exemplos mencionados indicam que as ações da Auxiliar decorrem de um conhecimento construído por ela na interação com os bebês no berçário por longa jornada diária. Tais conhecimentos operam nas condições de bem-estar das crianças, uma das finalidades da Educação Infantil e atribuição das professoras. Assim, observa-se que se trata de trabalho docente precarizado (PINTO, DUARTE e VIEIRA, 2012; VIEIRA e OLIVEIRA, 2013; TARDIF e LESSARD, 2014; CAMPOS, 1994; OLIVEIRA, 2004), na medida em que é exercido por profissional sem qualificação formal para a docência e em condições de trabalho inferiores às das professoras. Dessa forma, as ações realizadas pelas auxiliares são, portanto, duplamente invisibilizadas como discutido por Molinier (2012): por se tratar de ações que não geram um resultado visível e possa perdurar no tempo e ser reconhecido e por incluir ações que, se reconhecidas, serão atribuídas às professoras.

Outro elemento que se destaca de forma intimamente relacionada ao discutido acima refere-se ao vínculo que a Auxiliar constrói com as crianças. Embora esse aspecto esteja ausente das atribuições do cargo, como descrevemos na introdução deste trabalho, observa-se que essa profissional de fato se constitui em referência para as crianças, o que é reconhecido pelas professoras, e confirma o que Soares 
(2012) afirma a respeito do trabalho de cuidado com outro. No trecho a seguir, já reproduzido acima, a professora expressa seu reconhecimento do vínculo entre a Auxiliar e a bebê:

Uma Professora falou com a Auxiliar, referindo-se a uma criança que estava em processo de inserção na instituição e chorava praticamente todo o dia: "ela fica com você, mas é bom. Agora ela tem alguma referência. Daqui a pouco ela vai gostar de outras pessoas. Isso é bom. É porque você fica o dia todo"(notas de campo, 2017).

Os dados apresentados apontam para um conhecimento mais amplo da auxiliar sobre as(os) bebês do que o que possuem as professoras. Esse conhecimento pode sim ser decorrente do período de tempo que a auxiliar passa com as crianças (8 horas por dia), que é mais que o dobro de tempo que as professoras convivem com elas (3 horas). Mas, a observação indica que não é apenas o tempo que resulta em maior conhecimento. Na medida em que o tipo de relação e as ações decorrentes do cuidado e educação dos bebês exige a mobilização de habilidades como observação, atenção e afeto, bem como conhecimentos sobre as crianças em geral e, em particular, sobre aquelas com as quais atua cotidianamente, não se justifica a hierarquização das ações, muito menos a menor exigência de formação profissional. Parece-nos fundamental dedicar atenção às formas como as relações ocorrem no ambiente da instituição de Educação Infantil, pois se nos ativermos apenas às normas, como é o caso da descrição de atribuição da função de Auxiliar (GERÊNCIA..., 2015), pouco poderemos compreender e, consequentemente, contribuir para uma organização do trabalho que favoreça o bem-estar das crianças em jornada integral. As condições concretas em que as relações ocorrem definem as formas como o cuidado e educação das crianças acontecem.

\section{Considerações finais}

As relações estabelecidas entre as Professoras e a Auxiliar influenciam diretamente nas atividades da rotina com as(os) bebês. No caso da Auxiliar, o contrato de trabalho precário (via Caixa Escolar e não por concurso público) e a ausência de formação específica para o trabalho de cuidar e educar bebês limitam sua autonomia nas decisões sobre as atividades. Contudo, observa-se que a Auxiliar possui informações que as professoras não são capazes de adquirir pela limitação temporal de convivência com as crianças e pela criação de vínculos afetivos.

Nas situações concretas observadas, há contradição quanto a criação de uma função voltada apenas para o cuidado, quando as normas e concepções da área definem a indissociabilidade entre cuidar e educar. Observamos ainda que a atuação da Auxiliar vai além das funções determinadas para o exercício do seu trabalho sem que isso esteja explícito, o que impede que seja objeto de reconhecimento e da reflexão, condição necessária para a qualidade do trabalho com as(os) bebês.

Durante todo o dia de trabalho a Auxiliar participa dos diálogos, planejamentos e das ações que são realizadas durante toda a rotina. Mesmo que não verbalize, nem opine nas discussões, ela adquire informações importantes sobre o desenvolvimento das(os) bebês, bem como sobre o trabalho pedagógico

O trabalho docente no berçário exige intensa interação entre todas as adultas que nele atuam. As professoras e a auxiliar o fazem na rotina diária, de diferentes formas, a partir das necessidades da turma, 
bem como dos planejamentos realizados pelas professoras. A atenção ao trabalho da auxiliar permite também melhor compreensão das vivências dos bebês em jornada integral, pois esta é a única adulta que os acompanha o dia todo. Contraditoriamente, é a única adulta que não possui conhecimentos pedagógicos formalizados por meio da formação docente. É, também, a única adulta na turma que não participa da construção dos planejamentos previamente, tendo seu trabalho subordinado às Professoras. No entanto, como vimos, isto não impede que sua atuação ultrapasse o que está formalmente definido para a função de auxiliar. Isto demanda maior conhecimento das condições gerais de exercício da docência na Educação Infantil de modo a aquilatar os sentidos e repercussões das opções feitas pelas políticas públicas no que se refere aos profissionais para atuarem com as crianças pequenas nas Instituições de Educação Infantil.

\section{Referências}

AMORIM, Ana L. N. de. Sobre educar na creche: é possível pensar em currículo para crianças de zero a três anos? 2011. 338f. Tese (Doutorado em Educação) - Universidade Federal da Paraíba, João Pessoa, 2011.

BARBOSA, Maria C. As especificidades da ação pedagógica com os bebês. Anais do Seminário Nacional: Currículo em Movimento - Perspectivas atuais. Belo Horizonte, 2010.

Por amor e por força: rotinas na educação infantil. Porto Alegre: Artmed, 2006.

BARDIN, L. Análise de conteúdo. Lisboa: Edições 70, 2011.

BECKER, Scheila M. da S; MARTINS, Gabriela Dal F. Práticas e crenças de educadoras de berçário sobre cuidado. Psicologia em Estudo. V. 18, n. 3, p. 551-560, jul./set., 2013.

BELO HORIZONTE. Gerência de Coordenação da Educação Infantil. Ofício nº 277/2015.

BRASIL. Senado Federal. Constituição da República Federativa do Brasil. Brasília, DF: Senado Federal: Centro Gráfico, 1988.

Senado Federal. Lei de Diretrizes e Bases da Educação Nacional: nº 9394/96. Brasília, 1996. CAMPOS, Maria Malta. A formação de professores para crianças de $\mathbf{0}$ a 10 anos: modelos em debate. In: Educação \& Sociedade. Ano XX, nº 68, p. 126-142, Dez/1999.

Educar e cuidar: questões sobre o perfil do profissional de Educação Infantil. In: BRASIL. MEC/SEF/COEDI, Por uma política de formação do profissional de Educação Infantil. Brasília, 1994. 
CERISARA, Ana B. Educar e cuidar: por onde anda a Educação Infantil. Perspectiva, Florianópolis, v. 17, n. Especial, p. 11-21, jul./dez., 1999.

Professoras de educação infantil: entre o feminino e o profissional. São Paulo: Cortez, 2002.

CORDEIRO, Angélica M. A. O Sentido e o significado das práticas de cuidar e educar das educadoras de creche: as condições subjetivas e objetivas. [Mestrado] Universidade Federal de São Carlos, São Carlos, 2005.

COUTINHO, Ângela M. S. As crianças no interior da creche: a educação e o cuidado nos momentos de sono, higiene e alimentação. 2002. 165f. Dissertação (Mestrado em Educação) - Universidade Federal de Santa Catarina, Ilha de Santa Catarina, 2002.

DUMONT-PENA, Érica. Cuidar. Relações sociais, práticas e sentidos no contexto da Educação Infantil. 2015. 154f. Tese (Doutorado em Educação) - Universidade Federal de Minas Gerais, 2015.

FARIA, Ana Lúcia Goulart. Políticas de regulação, pesquisa e pedagogia na Educação Infantil, primeira etapa da Educação Básica. Educação \& Sociedade. Campinas, v. 26, n. 92, p. 1013-1038, Especial, Out., 2005.

GUIMARÃES, Daniela de O. Relações entre crianças e adultos no berçário de uma creche pública na cidade do Rio de Janeiro: técnicas corporais, responsividade, cuidado. 2008. 222f. Tese (Doutorado em Educação) - Universidade Católica do Rio de Janeiro, Rio de Janeiro, 2008.

GUIMARÃES, Nadya Araújo; HIRATA, Helena; SUGITA, Kurumi. Cuidado e cuidadoras: o trabalho do careno Brasil, França e Japão. In: HIRATA, H.; GUIMARÃES, N. A. (org.).Cuidado e Cuidadoras: as várias faces do trabalho do care. São Paulo: Atlas, 2012.

HADDAD, Lenira. A ecologia da Educação Infantil: construindo um modelo de sistema unificado de cuidado e educação. 1997. 336f. Tese (Doutorado em Educação) - Faculdade de Educação - Universidade de São Paulo. São Paulo, 1997.

HIRATA, Helena; GUIMARÃES, Nadya Araújo. Introdução. In: HIRATA, H.; GUIMARÃES, N. A. (org.). Cuidado e Cuidadoras: as várias faces do trabalho do care. São Paulo: Atlas, 2012. 
KISHIMOTO, T. M. Política de formação profissional para a educação infantil: Pedagogia e Normal Superior. Educação \& Sociedade. Campinas: nº 68, p. 61-79, 1999.

KRAMER, Sônia. Formação de profissionais de educação infantil: questões e tensões. In: MACHADO, A. L. de A. (org.). Encontros e desencontros em Educação Infantil. São Paulo: Cortez, 2002.

MARANHÃO, Damaris G. O cuidado como elo entre a saúde e a educação: um estudo de caso no berçário de uma creche. 1998. 150f. Dissertação (Mestrado em Educação) - Universidade de São Paulo, São Paulo, 1998.

O Cuidado como ele entre a saúde e a educação. Cadernos de Pesquisa, nº III, p. 115-133. Dez, 2000.

O cuidado de si e do outro. Revista Educação. Número Temático: Educação Infantil, out. 2011, pp.14-29.

MARANHÃO, Damaris G.; SARTI, Cynthia A. Cuidado compartilhado: negociações entre famílias e profissionais em uma creche. Interface - Comunicação, Saúde, Educação, v. 11, n. 22, p. 257-270, mai./ago., 2007.

MARANHÃO, D. G.; SANTOS, T. M.; COIMBRA, R. S. R.; CLEMENTE, D. R.; BARROS, E. M. Observar as crianças para integrar saúde e educação. Revista Veras, São Paulo, v. 5, n. 2, p. 133-147, julho/dezembro, 2015.

MINAYO, Maria C. de S. Análise qualitativa: teoria, passos e fidedignidade. Revista Ciência e Saúde Coletiva. No 17; p. 621-626, 2012.

MOLINIER, Pascale. Ética e trabalho do care.In: HIRATA, H.; GUIMARÃES, N. A. (org.) Cuidado e Cuidadoras: as várias faces do trabalho do care. São Paulo: Atlas, 2012.

MONTENEGRO, Thereza. Educação Infantil: a dimensão moral da função de cuidar. Psicologia da Educação. No 20, jun., 2005.

NASCIMENTO, Sandra J. do. Cuidar e educar: concepções de professoras de um centro de Educação Infantil na cidade de São Paulo. 2009. 162f. Dissertação (Mestrado em Educação) - Universidade de São Paulo, São Paulo, 2009. 
NAZARIO, Roseli. A “boa creche” do ponto de vista das professoras da Educação infantil. 2002. 102f. Dissertação (Mestrado em Educação) - Universidade Federal de Santa Catarina, Florianópolis, 2002.

OLIVEIRA-FORMOSINHO, J. O desenvolvimento profissional das educadoras de infância: entre os saberes e os afectos, entre a sala e o mundo. In: MACHADO, A. L. de A. (org.). Encontros e desencontros em Educação Infantil. São Paulo: Cortez, 2002.

OLIVEIRA, Zilma M. R. A Universidade na formação dos profissionais de educação infantil.In: Por uma política de formação do profissional de Educação Infantil. MEC/SEF/COEDI - Brasília, p. 64-68, 1994.

OLIVEIRA, D. A. A reestruturação do trabalho docente: precarização e flexibilização. Educação \& Sociedade, v. 25, n. 89, p. 1127-1144, dez., 2004.

PIMENTA, Selma Garrido. Saberes pedagógicos e atividade docente. 4 ed. São Paulo: Cortez, 2006.

PINTO, M. G. N.; DUARTE, A. M. C.; VIEIRA, L. M. F. O trabalho docente na educação infantil pública de Belo Horizonte. Revista Brasileira de Educação. V. 17, n. 51, set./dez., 2012.

SILVA, Isabel de O. e. Profissionais de creche no coração da cidade: a luta pelo reconhecimento profissional em Belo Horizonte. 2004. 297f. Tese (Doutorado em Educação) - Universidade Federal de Minas Gerais, Belo Horizonte, 2004.

Educação Infantil no Brasil. Pensar a Educação em Revista. Curitiba/Belo Horizonte, v. 2, n. 1, p. 03-33, jan-mar, 2016.

Professoras da Educação Infantil:formação, identidade e profissionalização. In: Docência na Educação Infantil. Ano XXIII, Boletim 10, p. 28-35, Jun/2013.

O trabalho docente na educação infantil: dilemas e tensões. In: Anais da $30^{\mathrm{a}}$ Reunião Anual da Anped, Caxambu -MG, p. 1-18, 2007..

SILVA, Isabel de Oliveira e.; VIEIRA, Lívia M. Fraga. Educação Infantil: bases históricas, políticas e sociais. Belo Horizonte: FAE/UFMG/UAB, 2008.

SOARES, Ângelo. As emoções do care.In: HIRATA, H.; GUIMARÃES, N. A. Cuidado e Cuidadoras: as várias faces do trabalho do care. São Paulo: Atlas, 2012. 
TARDIF, M; LESSARD, C. Trabalho docente: elementos para uma teoria da docência como profissão de interações humanas. 9 ed. Petrópolis, RJ: Vozes, 2014.

VIEIRA, Lívia Maria Fraga. O perfil das professoras e educadoras da Educação Infantil no Brasil.In: Docência na Educação Infantil. Ano XXIII, Boletim 10, p. 16-27, Jun/2013.

VIEIRA, L. M. F.; OLIVEIRA, T. G. As condições do trabalho docente na educação infantil no Brasil: alguns resultados de pesquisa (2002-2012). Revista Educação em Questão. Natal: RN, v. 46, n. 32, p. 131-154, maio/ago., 2013.

VITTA, Fabiana C. F. de.Cuidado e educação nas atividades do berçário e suas implicações na atuação profissional para o desenvolvimento e inclusão da criança de 0 a 18 meses. 2004. $177 f$. Tese (Doutorado em Educação Especial) - Universidade Federal de São Carlos, 2004. 